\title{
Long-term effectiveness of ranibizumab for age-related macular degeneration and diabetic macular edema
}

This article was published in the following Dove Press journal:

Clinical Interventions in Aging

26 April 2013

Number of times this article has been viewed

\author{
Angie HC Fong' \\ Timothy YY Lai ${ }^{1,2}$ \\ 'Department of Ophthalmology \\ and Visual Sciences, The Chinese \\ University of Hong Kong, Hong Kong \\ Eye Hospital, Kowloon, Hong Kong; \\ ${ }^{2} 2010$ Retina and Macula Centre, \\ Tsimshatsui, Kowloon, Hong Kong
}

\begin{abstract}
Neovascular age-related macular degeneration (AMD) and diabetic macular edema (DME) are major causes of visual impairment in the elderly population worldwide. With the aging population, the prevalence of neovascular AMD and DME has increased substantially over the recent years. Vascular endothelial growth factor (VEGF) has been implicated as playing an important role in the pathogenesis of both neovascular AMD and DME. Since its introduction in 2006, ranibizumab, a recombinant, humanized, monoclonal antibody fragment against all isoforms of VEGF-A, has revolutionized the treatment of neovascular AMD and DME. The efficacy and safety of ranibizumab in neovascular AMD has been demonstrated in the ANCHOR and MARINA trials. Further studies including the PIER, PrONTO, and SUSTAIN trials have also evaluated the optimal dosing regimen of ranibizumab in neovascular AMD. The CATT and IVAN trials compared the safety and efficacy of ranibizumab with off-label use of bevacizumab. Studies such as SUSTAIN and HORIZON have shown that ranibizumab has a good safety profile and is well tolerated for over 4 years with very few serious ocular and systemic adverse events. For DME, Phase II RESOLVE study and Phase III RISE and RIDE studies have demonstrated superiority of ranibizumab treatment in improving vision over placebo controls. Phase II READ and Phase III RESOLVE and REVEAL studies have shown that ranibizumab is more effective both as monotherapy and in combination with laser compared with laser monotherapy. The 3-year results from the DRCRnet protocol I study found that ranibizumab with deferred laser resulted in better long-term visual outcome compared with ranibizumab with prompt laser. This review summarizes various important clinical trials on the long-term efficacy and safety of ranibizumab in the treatment of neovascular AMD and DME. The pharmacological properties of ranibizumab, its cost effectiveness, and impact on quality of life will also be discussed.
\end{abstract}

Keywords: ranibizumab, anti-VEGF therapy, age-related macular degeneration, diabetic macular edema, safety, diabetic retinopathy, cost-effectiveness

\section{Introduction}

\section{Neovascular age-related macular degeneration}

Age-related macular degeneration (AMD) is a major cause of blindness in the elderly population. Epidemiological studies from pooled data have estimated the prevalence of early AMD and late AMD were $6.8 \%$ and $1.5 \%$ in whites aged 40 years or older, respectively. ${ }^{1}$ Similar prevalence figures have been found in Asian populations. ${ }^{2}$ AMD can be classified into nonexudative (dry) or neovascular (wet) forms. The former is characterized by abnormal deposits known as drusen at the macula and progressive atrophy of photoreceptors and retinal pigment epithelial cells in the macula, whereas the latter is characterized by the formation of abnormal blood vessels known as
Correspondence: Timothy YY Lai Department of Ophthalmology and Visual Sciences, The Chinese University of Hong Kong, Hong Kong Eye Hospital, I47K Argyle Street, Kowloon, Hong Kong

Tel +85227623134

Fax +852 27I5 9490

Email tyylai@cuhk.edu.hk 
choroidal neovascularization (CNV). If left untreated, the visual prognosis for eyes with neovascular AMD is poor. Nearly $15 \%$ of early AMD will progress to late AMD in 15 years. ${ }^{3}$ For neovascular AMD, the visual loss is progressive with approximately one line of vision lost at 3 months, three lines at 1 year, and four lines at 2 years. ${ }^{4}$

Vascular endothelial growth factor (VEGF)-A has been implicated as a major factor in the angiogenesis and progression of neovascular AMD. VEGF-A promotes the growth of vascular endothelial cells and increases vascular permeability. It plays a key role in embryonic vasculogenesis including the development of choroidal vasculature, and is an important mediator in tumor angiogenesis. ${ }^{5}$ Previous immunohistological studies have localized VEGF in surgically resected $\mathrm{CNV}$, implying VEGF plays an important role in $\mathrm{CNV}$ development. ${ }^{6}$ Complement activation and inflammation, with subsequent vascular damage, is thought to play a role in the upregulation of VEGF-A in neovascular AMD. $^{7}$

Until the advent of antivascular endothelial growth factor (anti-VEGF) therapy, treatment of neovascular AMD has been far from optimal. Photodynamic therapy (PDT) with verteporfin was first introduced for treating neovascular AMD in 2000 and treatment aimed to stabilize vision rather than improve vision. ${ }^{8}$ It involves a two-stage process where the photosensitizing agent verteporfin is activated by an infrared laser, which then releases free oxygen radicals to damage the vascular endothelium, resulting in vascular occlusion of the CNV. Two large randomized control trials (TAP and VIP studies), ${ }^{9,10}$ demonstrated the usefulness of PDT in preventing moderate visual loss of 3 or more lines in patients with subfoveal CNV due to AMD. However, there was still a mean decline in visual acuity (VA) of 9.8 letters over 2 years. ${ }^{10}$

In 2006, the efficacy of intravitreal ranibizumab injections (Lucentis; Genentech, South San Francisco, CA, USA and Novartis, Basel, Switzerland) in the treatment of predominately classic, minimally classic and occult subfoveal choroidal CNV in neovascular AMD were demonstrated by the ANCHOR and MARINA trials. ${ }^{11,12}$ For the first time, patients can expect improvement in vision rather than maintenance of vision. Safety profile and optimal dosing schedule to reduce the frequency of injections while maintaining visual gain have been investigated in various subsequent studies including PIER, PrONTO, SUSTAIN, HORIZON, CATT, and IVAN. ${ }^{13-18}$ Long-term studies have shown that ranibizumab is well tolerated for over 4 years and has been shown to have very few serious ocular and systemic side effects. ${ }^{16}$

\section{Diabetic macula edema}

Diabetic macular edema (DME) is a major complication of diabetic retinopathy (DR) and is the most frequent cause for preventable blindness in working adults in many countries. ${ }^{19}$ A large meta-analysis has estimated the overall prevalence of any DR to be $34.6 \%$, and the prevalence of DME was $6.8 \% .^{20} \mathrm{DME}$ is caused by leakage from the abnormal retinal capillaries leading to macular thickening and edema. If left untreated, a considerable proportion of patients with DME will suffer from visual loss. The Early Treatment for Diabetic Retinopathy Study group (ETDRS) found that without treatment, over $30 \%$ of eyes with DME developed visual loss of three lines or more at 3 years. ${ }^{21}$ Until recently, macular laser photocoagulation had been the standard of treatment for DME. Although grid laser photocoagulation can result in a $50 \%$ risk reduction of moderate visual loss, the treatment is limited to vision stabilization or minimal mean improvement in vision. ${ }^{21}$ Intravitreal steroids such as triamcinolone acetonide, fluocinolone, and dexamethasone has also been used in the treatment of DME, but they are associated with side effects such as cataract formation and increased intraocular pressure. ${ }^{22}$

VEGF has been found to play an important role in the development of DME. The hypoxic retina triggers the production of VEGF from retinal pigment epithelial cells, pericytes, and endothelial cells, which in turn causes breakdown of the blood-retinal barrier, leading to DME. Anti-VEGF therapy with ranibizumab for the treatment of DME has been established in multiple Phase II and III studies. ${ }^{23-29}$ Based on these findings, ranibizumab has also been approved by various regulatory authorities for the treatment of DME.

In this article, we aim to review the major clinical trials regarding the long-term efficacy and safety of ranibizumab in the treatment of AMD (Table 1) and DME (Table 2). The pharmacological properties of ranibizumab, cost-effectiveness, impact on the quality of life, as well as future directions will also be discussed.

\section{Overview of pharmacology of ranibizumab Ranibizumab molecule}

Ranibizumab is a recombinant, humanized monoclonal antibody antigen-binding fragment (Fab) directed against VEGF-A. VEGF-A belongs to a family of mitogenic glycoproteins that promote angiogenesis by the activation of cell surface VEGF receptors present in endothelial and mural cells via a tyrosine kinase (TK) signaling pathway. Besides VEGF-A, other factors in the gene family includes placental 
growth factor (PlGF), VEGF-B, VEGF-C, VEGF-D, and the orf virus-encoded VEGF-E. ${ }^{30}$ Six major isoforms of VEGF-A have been identified by alternative splicing: VEGF121, VEGF-145, VEGF-165, VEGF-183, VEGF-189, and VEGF-206, where VEGF-165 is the predominant isoform. ${ }^{31}$ Ranibizumab acts against all VEGF isoforms of VEGF-A and was found to be more effective in treating neovascular AMD than another anti-angiogenesis agent, pegaptanib sodium (Macugen, Pfizer/OSI Eyetech, New York, NY, USA), which is a pegylated ribonucleic acid aptamer that acts against only the VEGF-165 isoform. ${ }^{32}$

Ranibizumab is produced in an Escherichia coli expression system and has a molecular weight of around $48 \mathrm{kD} .^{33}$ The molecule consists of a light and heavy chain with one antibody-binding site. On a molar basis, ranibizumab is found to be 5 to 20 times more potent than the full-length antibody bevacizumab in vitro. ${ }^{5}$ Due to the small molecular size of ranibizumab as an antibody fragment, the molecule can penetrate all layers of the retina more readily than the bevacizumab antibody (molecular weight of $148 \mathrm{kD}) .{ }^{5}$ The absence of the $\mathrm{F}_{\mathrm{c}}$ portion of the antibody in ranibizumab also eliminates the possibility of complement-mediated or cell-dependent cytotoxicity triggered by interaction of the $F_{c}$ receptors with inflammatory cells. ${ }^{5}$

\section{Development of ranibizumab}

In 1993, a murine monoclonal antibody (Mab) targeting human VEGF-A was developed and it has been shown to be able to inhibit tumor growth in vivo. ${ }^{34}$ The humanized form of the murine Mab, which was a full-length immunoglobulin $\mathrm{G}$ (IgG) was later named bevacizumab. ${ }^{35}$ Bevacizumab was approved by the US Food and Drug Administration for treatment of metastatic colorectal cancer as an adjuvant chemotherapy. However, systemic administration of bevacizumab for neovascular AMD has raised safety concerns due to the potential increased incidence of arterial thromboembolic events. ${ }^{36}$ Therefore, an intravitreal anti-VEGF agent was developed to provide local therapy for neovascular AMD. The Fab portion of bevacizumab (Fab-12) was found to be more diffusible and demonstrated increased penetration through the retina into the choroid and was therefore used instead of the full-length antibody. ${ }^{5}$ To increase potency and binding affinity of Fab-12 to VEGF-A molecules, five variable domain substitutions and one constant domain substitution of Fab-12 was engineered through a series of recombinant DNA and phage-display selection steps, resulting in Fab rhuFabV2 or ranibizumab which is around 100 times more potent than Fab-12.5

\section{Pharmacodynamics and pharmacokinetics of ranibizumab}

Ranibizumab is delivered by direct intravitreal injection into the eye through the pars plana. The drug penetrates all layers of the retina to reach the choriocapillaris, where the CNV in AMD originate. It binds to the receptor-binding site of active forms of VEGF-A and prevents VEGF-A from binding to its receptors (VEGFr-1 and VEGFr-2) on the endothelial cell surface, thus reducing vascular permeability and formation of new vessels. ${ }^{37}$ In animal studies, it was found that ranibizumab inhibited the vascular permeability-enhancing activity of VEGF-110, VEGF-121, and VEGF-165 in human umbilical vein endothelial cell proliferation in a dose-dependent fashion. ${ }^{38}$

Preclinical pharmacokinetic studies performed in monkeys have demonstrated that a single injection of $0.5 \mathrm{mg}$ ranibizumab reaches a peak vitreous concentration after 6 hours..$^{39,40}$ There is rapid distribution of the drug from the vitreous into either the retina or the aqueous chamber, where the concentration in the retina is around one-third of that in the vitreous. The drug is then cleared in parallel from all ocular compartments. The estimated vitreous elimination half-life of ranibizumab in humans is around 7 days, ${ }^{41}$ and the elimination half-life from the systemic circulation is around 2 hours. ${ }^{42}$ Following a single intravitreal injection of $0.5 \mathrm{mg}$ ranibizumab in AMD patients, the maximal serum concentration was found at 1 day at a level 90,000 times less than the intravitreal ranibizumab exposure and is well below the concentration necessary to inhibit the biological activity of VEGF by $50 \%{ }^{42}$

\section{Efficacy, safety, and tolerability of ranibizumab in neovascular AMD in major clinical trials ANCHOR and MARINA}

The efficacy and safety of ranibizumab in the treatment of neovascular AMD has been established in two Phase III prospective, randomized, double-blind, international multicenter clinical trials: the ANCHOR (Anti-VEGF Antibody for the Treatment of Predominantly Classic CHORoidal Neovascularization in AMD) and MARINA (Minimally classic/ occult trial of the Anti-VEGF antibody ranibizumab In the treatment of Neovascular AMD) trials. ${ }^{11,12}$ In the ANCHOR trial, 423 patients with predominantly classic CNV due to neovascular AMD were randomized to PDT every 3 months as needed, or monthly intravitreal injection of either $0.3 \mathrm{mg}$ or $0.5 \mathrm{mg}$ ranibizumab. ${ }^{11}$ Results at the end of 2 years showed 


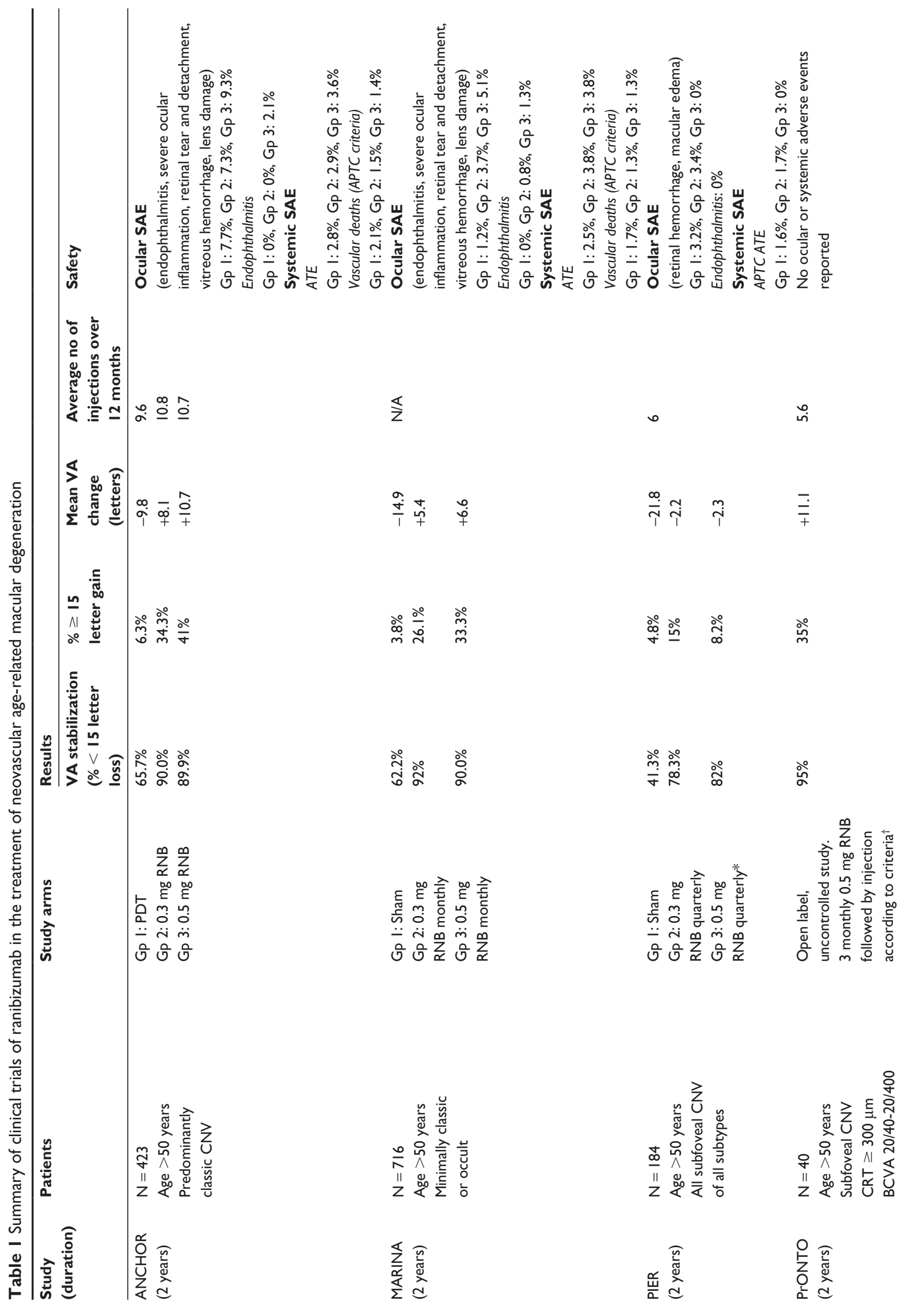




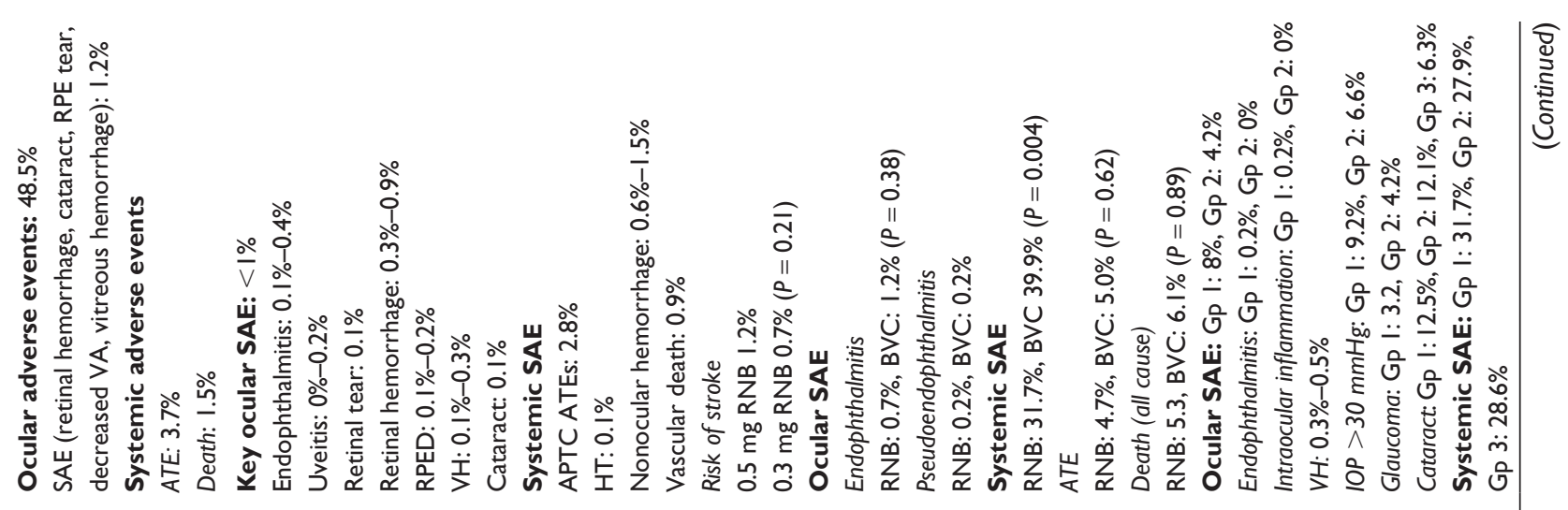

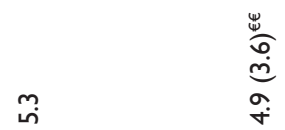

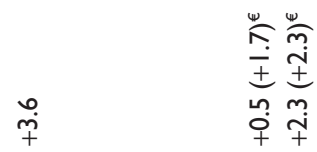

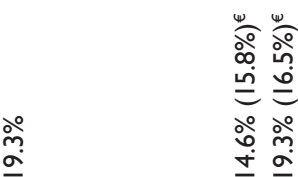

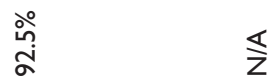

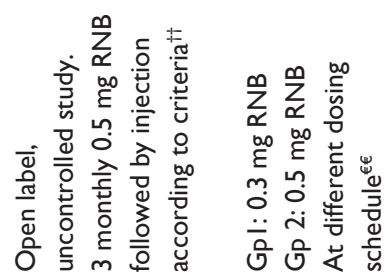

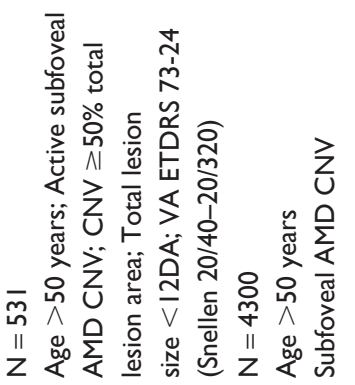

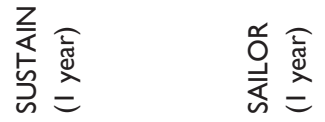

ํㅗㄹ

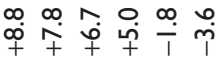

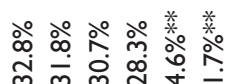

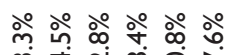

ऊूँ

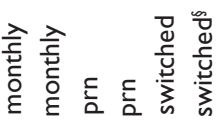

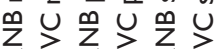

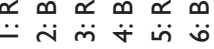

윙 응 응 응 응 응
䓫

ㄱำ

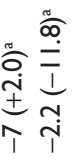

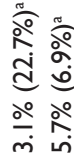

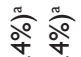

逐

○ั

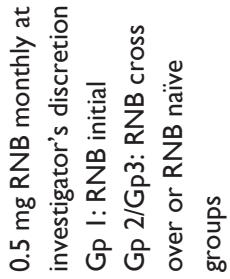

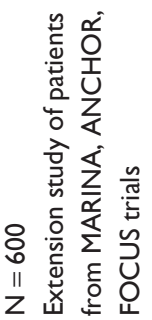

歺竞 


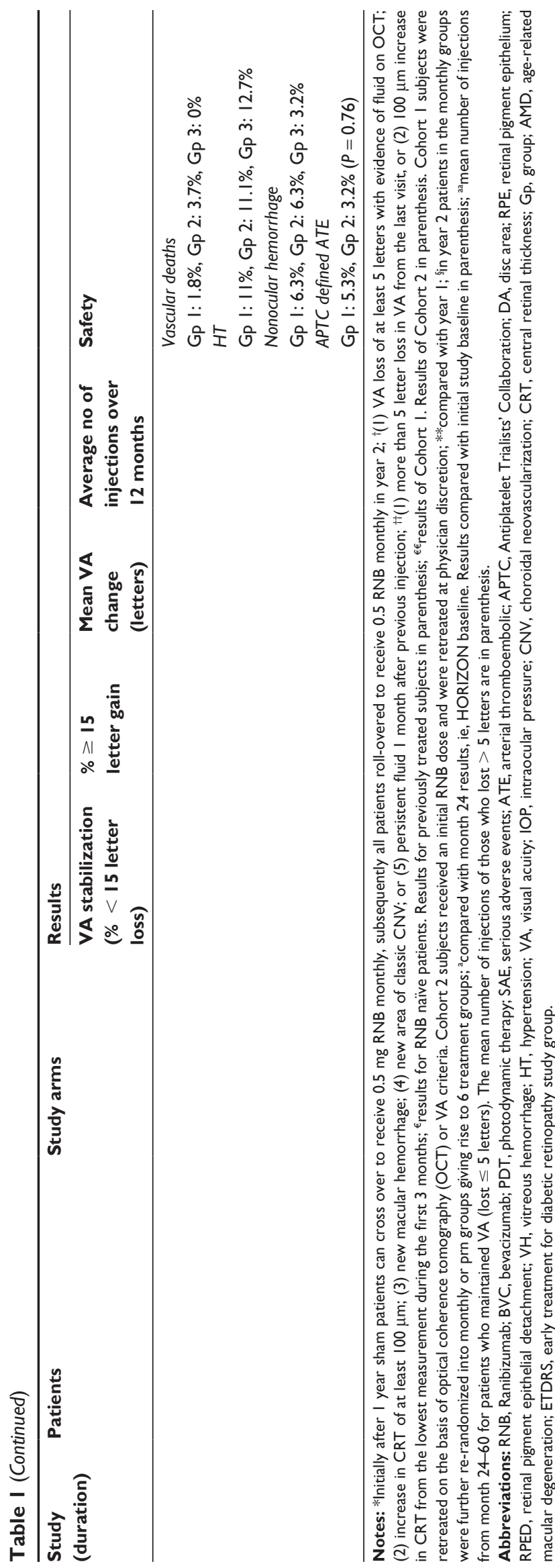

that $89.9 \%$ of the $0.3 \mathrm{mg}$ and $0.5 \mathrm{mg}$ ranibizumab groups lost fewer than 15 letters of VA compared with $65.7 \%$ of the PDT-treated group. In addition, $41 \%$ of the 0.5 -mg-treated group and $34 \%$ of the $0.3-\mathrm{mg}$-treated group gained at least 15 letters of vision, compared with only $6.3 \%$ in the PDTtreated group. The mean VA improved by +8.1 and +10.7 letters in the $0.3 \mathrm{mg}$ and $0.5 \mathrm{mg}$ ranibizumab groups, respectively, while there was a 9.8-letter drop in vision in the PDT-treated group. ${ }^{11}$

While the ANCHOR trial assessed the efficacy of ranibizumab in predominately classic CNV, the MARINA trial assessed the efficacy and safety of ranibizumab in minimally classic or occult CNV. ${ }^{12}$ Seven hundred sixteen patients were randomized to either monthly placebo injections, $0.3 \mathrm{mg}$ or $0.5 \mathrm{mg}$ ranibizumab injections over a period of 2 years. Results showed that $90 \%$ of the $0.5 \mathrm{mg}$ ranibizumab-treated eyes avoided visual loss of $\geq 3$ lines of vision, compared to $62.2 \%$ in the placebo injection group. In terms of visual gain, significantly higher proportion of patients gained $\geq 3$ lines compared with controls, with $25 \%$ and $33.8 \%$ in the $0.3 \mathrm{mg}$ and $0.5 \mathrm{mg}$ ranibizumab groups, respectively. There was a mean visual gain of 6.6 letters at 2 years for the $0.5 \mathrm{mg}$ ranibizumab group, compared with a mean loss of 14.9 letters in the control group $(P<0.001) .{ }^{12}$

Both the ANCHOR and MARINA trials showed that ranibizumab is generally safe and well tolerated. No significant difference in ocular and nonocular adverse events was found in the ranibizumab groups compared with PDT or placebo controls. ${ }^{11,12}$ Serious ocular adverse events included endophthalmitis, uveitis, vitreous hemorrhage, rhegmatogenous retinal detachment, retinal tear, or lens damage. In the 2-year ANCHOR study, the cumulative incidence of endophthalmitis was $2.1 \%{ }^{11}$ and the endophthalmitis rate in the 1-year MARINA trial was $1.3 \%{ }^{12}$ In the MARINA trial, there was a small difference in arterial thromboembolic events (ATE) between the placebo and ranibizumab groups ( $2.5 \%$ versus $3.8 \%)$, but the difference was not statistically significant.

\section{PIER}

Although ranibizumab was found to be effective in the treatment of AMD, with monthly dosing, cost quickly became an issue of concern. If given monthly at the recommended dosage of $0.5 \mathrm{mg}$ for neovascular AMD, the ranibizumab drug cost alone can accumulate to US\$24,000 per year. In order to address this issue, the PIER study was performed to evaluate the efficacy and safety of a 3-monthly dosing regimen of ranibizumab for the treatment of neovascular AMD. ${ }^{13}$ 
One hundred eighty-four patients were randomized into placebo injection, $0.3 \mathrm{mg}$ or $0.5 \mathrm{mg}$ ranibizumab on a monthly or 3-monthly basis. During the second year, eligible placebo group patients could crossover to the $0.5 \mathrm{mg}$ ranibizumab quarterly and later all eligible patients were switched to $0.5 \mathrm{mg}$ ranibizumab monthly. At the end of 2 years, $78.3 \%$ and $82 \%$ of the $0.3 \mathrm{mg}$ and $0.5 \mathrm{mg}$ ranibizumab groups, respectively, lost less than three lines of vision, compared with $41.3 \%$ of the placebo injection group $(P<0.0001)$. There was a mean decrease in VA of 2.2 and 2.3 letters in the 0.3 and $0.5 \mathrm{mg}$ ranibizumab groups, respectively, compared with a 21.8-letter loss in the placebo-treated group $(P<0.0001)$. Quarterly dosing of ranibizumab resulted in a slight visual decline and patients who were switched to monthly ranibizumab injections after 1 year did not benefit in terms of VA. In terms of safety, there was no endophthalmitis, severe uveitis, or lens damage during the 2-year study period. The rate of ATE was $1.6 \%$ in the placebo group and $0 \%$ in the ranibizumab group in the first year. In the second year, for the postcrossover ranibizumab treatment groups, the rate of ATE was $1.7 \%$ for the $0.3 \mathrm{mg}$ group and $0 \%$ for the $0.5 \mathrm{mg}$ group.

\section{PrONTO}

As the 3-monthly dosing of ranibizumab was found to be inadequate in the treatment of AMD, a variable dosing regimen was evaluated in the PrONTO (Prospective Optical Coherence Tomography Imaging of Patients with Neovascular AMD treated with intra-Ocular Ranibizumab) study. ${ }^{14}$ It was a 2-year open-label single-center uncontrolled study in which the dosing regimen of ranibizumab was guided by optical coherence tomography (OCT) findings. Forty patients with subfoveal CNV and central retinal thickness (CRT) of at least $300 \mu \mathrm{m}$ were treated with three consecutive loading doses of $0.5 \mathrm{mg}$ ranibizumab at monthly intervals. Patients were given retreatment if any of the five criteria were met: (1) VA loss of at least 5 letters with evidence of fluid on OCT; (2) increase in CRT of at least $100 \mu \mathrm{m}$; (3) new macular hemorrhage; (4) new area of classic CNV; or (5) persistent fluid 1 month after previous injection. The second retreatment criterion was later amended to any qualitative increase in fluid detected on OCT. At 24 months, the mean VA improved by 11.1 letters and OCT CRT decreased by $212 \mu \mathrm{m}$. The mean number of injections decreased to 5.6 over 1 year and 9.9 over 2 years, compared with 24 injections as used in the ANCHOR and MARINA trials. Although the visual outcomes were better than that in the PIER trial, there was no control group in this study and it is unknown whether patients would have more visual gain with a monthly dosing regimen.

\section{SUSTAIN}

The Study of Ranibizumab in Patients with Subfoveal CNV Secondary to AMD (SUSTAIN) evaluated the safety and efficacy of $0.3 \mathrm{mg}$ (which was later switched to $0.5 \mathrm{mg}$ ) ranibizumab of pro re nata (prn) regimen in the treatment of AMD. ${ }^{15}$ It was a single-arm open-labeled study, with 531 patients given three initial loading injections and retreated on a monthly basis if there was: (1) more than 5 letter VA loss from the last visit, or (2) $100 \mu \mathrm{m}$ increase in CRT from the lowest OCT measurement during the first 3 months. At the end of 12 months, the mean number of injections given was 5.3. Patients had a mean gain of 5.8 letters at 3 months, which declined to 3.6 letters in the subsequent 9 months with prn dosing. There was a mean CRT decline of $91.5 \mu \mathrm{m}$ from baseline at month 12 . The overall safety profile was satisfactory, with $1.2 \%$ of patients developing ocular adverse events including retinal hemorrhage, cataract, and retinal pigment epithelial tear. Vitreous hemorrhage and ATE were observed in $3.7 \%$ of the patients.

\section{SAILOR}

The SAILOR study (The Safety Assessment of Intravitreal Lucentis fOR AMD) was a 12-month multicenter Phase IIIb study to evaluate the safety of ranibizumab in the treatment of neovascular AMD. ${ }^{43}$ Over 4,000 patients aged 50 years or older were divided into two treatment cohorts and received $0.3 \mathrm{mg}$ or $0.5 \mathrm{mg}$ ranibizumab at different dosing schedules. Results showed that ranibizumab is well tolerated with key ocular adverse events including endophthalmitis and pseudoendophthalmitis of less than $1 \%{ }^{43}$ For systemic safety, the results showed a slightly higher trend risk of stroke in the $0.5 \mathrm{mg}$ versus $0.3 \mathrm{mg}$ group ( $1.2 \%$ versus $0.6 \%$ ), but the difference was not statistically significant. Previous history of stroke, arrhythmia, and congestive heart failure were found to be risk factors for stroke in the study. However, since the study did not have a control arm, the increased stroke risk might be due to inherent risk factors for subsequent stroke rather than drug effect.

\section{CATT and IVAN}

Bevacizumab is widely used as an off-label anti-VEGF agent in the treatment of AMD due to its cheaper cost. The efficacy and safety of ranibizumab was compared with bevacizumab in the Ranibizumab and Bevacizumab for Treatment of Neovascular Age-related Macular Degeneration (CATT) study. ${ }^{17,44}$ It was the largest head-to-head trial comparing the two anti-VEGF drugs. Treatment-naïve patients with active subfoveal CNV secondary to AMD were randomized in a 
1:1:1:1 ratio into either $0.5 \mathrm{mg}$ ranibizumab monthly for 1 year, $1.25 \mathrm{mg}$ bevacizumab monthly for 1 year, $0.5 \mathrm{mg}$ ranibizumab prn, or $1.25 \mathrm{mg}$ bevacizumab prn. Patients who had prn treatment were given a single initial injection followed by prn injection every month depending on disease activity. At the end of 1 year, there was a mean gain of 8.5 and 8.0 letters for the monthly ranibizumab and bevacizumab groups, respectively, while there was a mean gain of 6.8 and 5.9 letters for the ranibizumab and bevacizumab prn groups, respectively. Bevacizumab was found to be noninferior to ranibizumab in terms of efficacy.

At the start of the second year, patients who were in the ranibizumab or bevacizumab monthly groups were rerandomized into ranibizumab or bevacizumab monthly, or switched to ranibizumab or bevacizumab prn groups, resulting in six different treatment arms. ${ }^{44}$ At the end of the second year, there was a mean visual gain of 8.8 letters and 7.8 letters for the ranibizumab and bevacizumab monthly group, respectively, with most gain in vision occurring during the first year. There was a mean gain of 6.7 and 5.0 letters for ranibizumab and bevacizumab prn group, respectively. For patients who switched to prn dosing from monthly dosing at the first year, there was a mean decline of 2.2 letters at the second year. The CRT on OCT also increased by $31 \mu \mathrm{m}$ in the switched ranibizumab group and $19 \mu \mathrm{m}$ in the switched bevacizumab group $(P=0.0004)$. Overall, no significant difference in VA was seen between bevacizumab and ranibizumab groups (mean change of 1.4 letters in favor of ranibizumab). However, a small but statistically significant difference of 2.4 letters was found in favor of monthly dosing compared with prn treatment. For secondary outcomes, it was found that more patients treated with ranibizumab monthly had no subretinal fluid on OCT compared with bevacizumab prn group (46\% versus $14 \%$; $P<0.05)$, and CRT was lower in the monthly than prn groups $(P=0.005)$. In terms of safety, there were statistically significantly more systemic serious adverse events with bevacizumab compared with ranibizumab. In particular, there was a higher rate of serious adverse events for bevacizumab from the first year, which persisted into the second year, with the greatest imbalance in gastrointestinal disorders. ${ }^{44}$ Nonetheless, the rates of death, stroke, and heart attack that might be associated with anti-VEGF agents were similar between the two drugs.

The IVAN study is a head-to-head trial similar to the CATT study performed in the UK to compare the efficacy and safety of bevacizumab and ranibizumab. ${ }^{18}$ In this study, 610 patients were randomized into continuous or noncontinuous dosing of ranibizumab or bevacizumab after three initial loading doses. The primary outcome of the CATT study was replicated in the IVAN study, as there was a noninferiority comparison between bevacizumab and ranibizumab in terms of visual change. In terms of treatment regimen, both continuous and discontinuous treatment was found to be equivalent in terms of visual change. However, CRT on OCT was found to be lower with continuous treatment.

In terms of safety, the IVAN study found that fewer patients in the bevacizumab group had ATE or heart failure and there was no significant difference in patients experiencing serious adverse events between the two drugs. ${ }^{18}$ However, a meta-analysis of 1-year data of three direct comparison trials showed a significantly higher rate of ocular adverse effects with bevacizumab (relative risk $[\mathrm{RR}]=2.8$; 95\% confidence interval [CI]: 1.2-6.5) and the proportion of patients with serious infectious and gastrointestinal disorders were also higher with bevacizumab than ranibizumab $(\mathrm{RR}=1.3 ; 95 \%$ CI: $1.0-1.7) .{ }^{45}$ Therefore based on these findings, ranibizumab might provide some safety advantages compared with bevacizumab.

\section{HORIZON}

The long-term safety of ranibizumab in the treatment of AMD was assessed in HORIZON, which is an open-labeled extension of patients who have completed the MARINA, ANCHOR, and FOCUS trials. ${ }^{16}$ Eligible patients received $0.5 \mathrm{mg}$ ranibizumab at monthly intervals at the investigator's discretion for 2 years. Patients were analyzed based on three groups: patients who were randomized to the ranibizumab group in the MARINA, ANCHOR, and FOCUS trials $(n=600)$; patients who were in the control groups and later switched to receiving ranibizumab $(\mathrm{n}=190)$; and ranibizumab-naïve group $(n=63)$. The main outcome measures of the study were incidence and severity of adverse events. Of the 3,552 injections in the study, there was only one case of mild endophthalmitis. There were no serious ocular adverse events such as lens damage, retinal tears, or rhegmatogenous retinal detachments. The incidence of high intraocular pressure over $30 \mathrm{mmHg}$ was low and was observed in $9.2 \%$ and $6.6 \%$ of the ranibizumab-treated group and the crossover group, respectively. Cataract progression was found to be more common in the ranibizumab-treated $(12.5 \%)$ and crossover $(12.1 \%)$ groups than the treatmentnaïve $(6.3 \%)$ group, but the differences were not statistically significant $(P=0.2)$. Systemically, the difference in incidence of ATE between the ranibizumab and control groups was not statistically significant $(5.3 \%$ versus $3.2 \% ; P=0.76)$. Therefore, the long-term use of repeated injections of ranibizumab was found to be safe in the study. 
In terms of visual outcome, there was a slight mean decline in the VA gain observed with the initial studies. With less frequent follow-up (mean duration of 2 months) and less rigorous injection schedule (mean of four injections over 2 years), there was a mean gain of 2.0 letters in the ranibizumab-treated groups, and a mean loss of 11.8 letters in the pooled ranibizumab crossover group and untreated group at 48 months. Therefore, the VA for the ranibizumab treated group remained stable over 4 years, while the control groups lost vision due to delayed initial treatment. The study concluded that ranibizumab is safe in the long term, but that there is an incremental decline VA gain with longer follow-up duration and less frequent dosing schedules.

\section{Efficacy, safety, and tolerability of ranibizumab in diabetic macula edema}

Several key studies have been published on the long-term efficacy and safety of ranibizumab in the treatment of DME, including Phase II RESOLVE and READ-2 studies ${ }^{23,25-27}$ and Phase II RISE and RIDE studies, ${ }^{24}$ RESTORE, ${ }^{28,46}$ REVEAL, ${ }^{47}$ and DRCRnet protocol I. ${ }^{29}$

\section{RESOLVE}

In the RESOLVE study, 102 patients with DME due to type 1 or 2 diabetes were randomized to either $0.3 \mathrm{mg}$ ranibizumab, $0.5 \mathrm{mg}$ ranibizumab, or placebo treatment. ${ }^{27}$ The ranibizumab-treated groups received three monthly loading doses followed by prn injection based on treatment success, disease activity, or safety criteria. After 1 month, the dose could be doubled to $0.6 \mathrm{mg}$ or $1.0 \mathrm{mg}$ if the CRT remained at $>300 \mu \mathrm{m}$ or if there was $<50 \mu \mathrm{m}$ reduction from the previous assessment. Results showed that at 1 year, the mean numbers of injections were 10.2 for the ranibizumab group and 8.9 for the placebo group. The primary outcome of the study was the mean average VA change from baseline (arithmetic mean of change in letter scores from month 1 through month 12) and was +7.8 letters for the pooled ranibizumab group, versus -0.1 letter in the placebo group. Secondary outcomes included the mean change in best-corrected VA at month 12 , which was +10.3 letters for the ranibizumab group and -1.4 letters for the placebo group. More than $60 \%$ of the patients in the ranibizumab group gained two lines of vision versus only $9 \%$ in the placebo group. Ranibizumab was found to be safe with ocular serious adverse events being comparable between the treatment and placebo groups. Systemically, the incidence of ATEs, hypertension, and nonocular hemorrhage were also found to be comparable between the ranibizumab and placebo arms.

\section{READ-2}

In the READ-2 study, ${ }^{25}$ ranibizumab was compared with laser or combination treatment. One hundred twenty-six patients with DME were randomized to either ranibizumab every 2 months, focal/grid laser every 3 months, or combined ranibizumab and focal/grid laser at baseline and at month 3 for the first 6 months. After 6 months, patients can crossover to ranibizumab group if the retreatment criteria were met. At 6 months, the mean change in vision was +7.2, -0.4, and +3.8 letters for the ranibizumab, laser, and combined groups, respectively. For patients who continued the study up to 2 years, most patients received ranibizumab and the mean visual gain at 2 years was 7.7, 5.1, and 6.8 letters for the ranibizumab, laser, and combined groups, respectively, with substantial improvement in the previously laser-treated group. At 3 years, the protocol was amended so that patients were monitored monthly instead of every 2 months and were given ranibizumab injections if central macular thickness (CMT) was found to be $\geq 250 \mu \mathrm{m} .{ }^{23}$ The greatest improvement in vision was seen in the ranibizumab group with more aggressive monitoring and treatment and the final mean VA improvement compared with baseline were 10.3, 1.4, and 8.9 letters for the three groups, respectively. Anatomically, all three groups showed improvement in terms of reduction in macula thickness on OCT. The study demonstrated that ranibizumab to be well tolerated with no retinal toxic effects among DME patients for up to 3 years. ${ }^{23}$

\section{RISE and RIDE}

RISE and RIDE studies are two parallel, 24-month, Phase III, double-masked randomized control trials comparing monthly ranibizumab versus placebo controls in the treatment of DME. ${ }^{24} \mathrm{~A}$ total of 377 patients (RISE) and 382 patients (RIDE) were randomized to either $0.3 \mathrm{mg}$ ranibizumab, $0.5 \mathrm{mg}$ ranibizumab, or placebo injection. They were given monthly injections followed by potential rescue laser at 3 months. At 24 months, the placebo group also switched to the $0.5 \mathrm{mg}$ ranibizumab group. The results showed that a significantly greater proportion of ranibizumab-treated patients had $\geq 15$ letters gain in vision compared with placebo group, with $44.8 \%$ (RISE) and 33.6\% (RIDE) for the $0.3 \mathrm{mg}$ ranibizumab groups, $39.2 \%$ (RISE) and $45.7 \%$ (RIDE) for $0.5 \mathrm{mg}$ ranibizumab groups, versus $18.1 \%$ (RISE) and $12.3 \%$ (RIDE) for the placebo groups $(P<0.0001)$. The mean change in vision was +12.5 letters (RISE) and +10.9 (RIDE) for the $0.3 \mathrm{mg}$ ranibizumab groups, +11.9 letters (RISE) and +12 letters (RIDE) for the $0.5 \mathrm{mg}$ ranibizumab groups versus +2.6 letters (RISE) and +2.3 letters (RIDE) in 


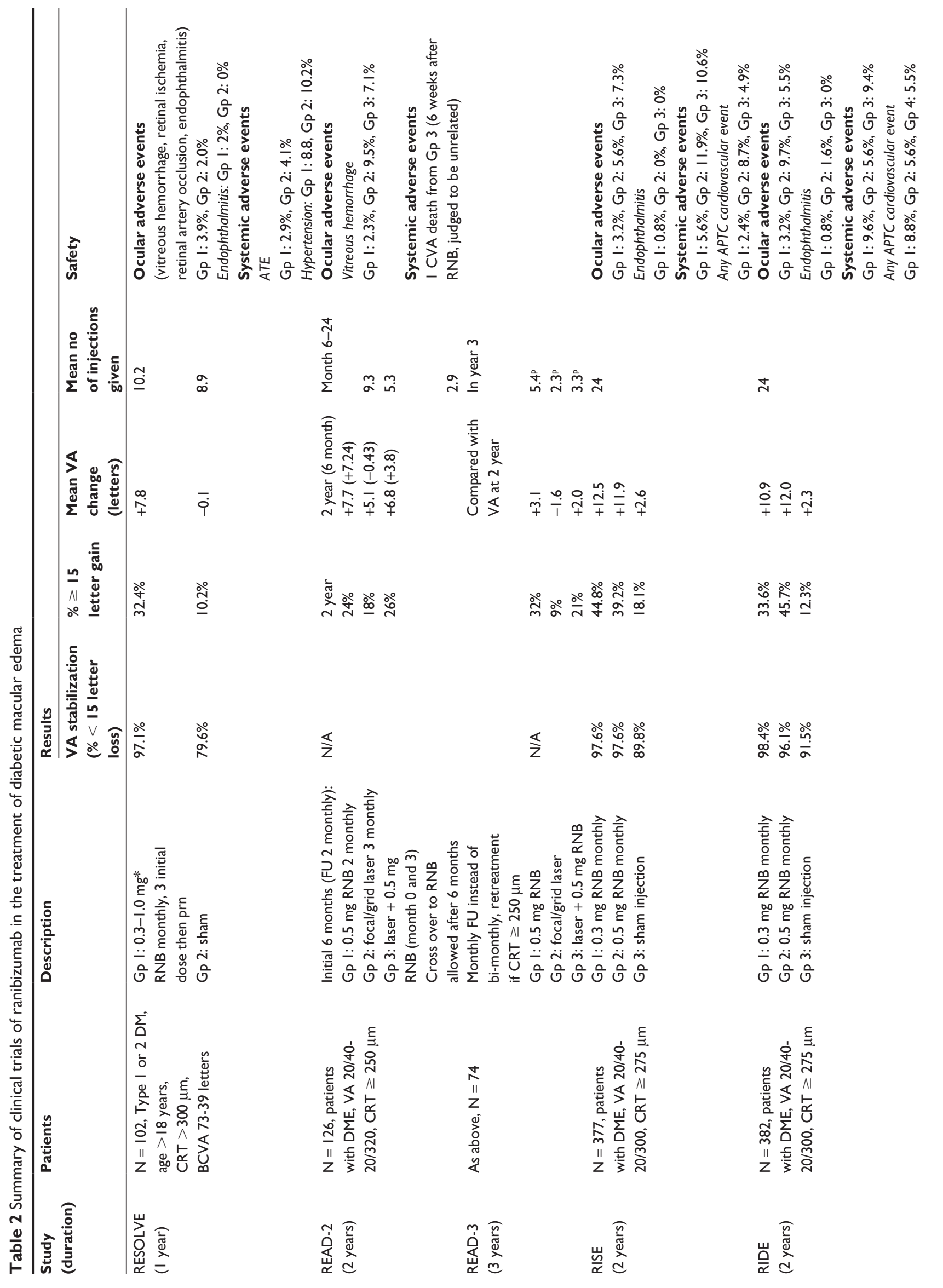




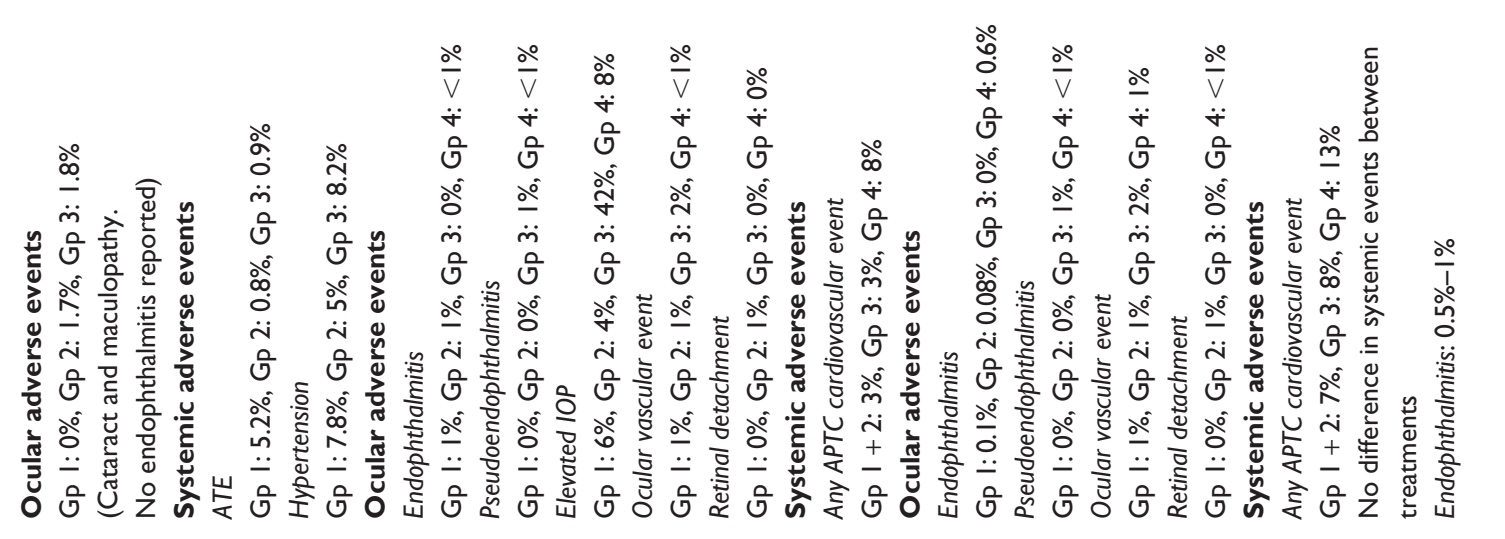

$\overline{0} \stackrel{0}{\circ} \stackrel{\infty}{+}$

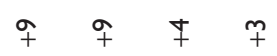

管 $\underset{+}{+}$

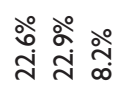

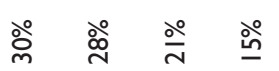

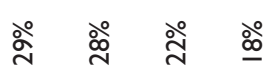

$\stackrel{\Psi}{\sim} \quad \stackrel{\Psi}{m} \stackrel{\Psi}{\Sigma}$

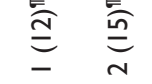

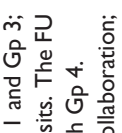

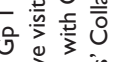

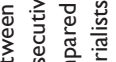

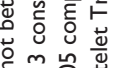

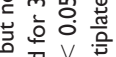

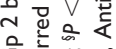

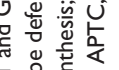

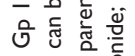

든

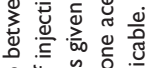

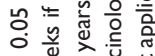

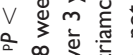

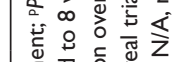

离

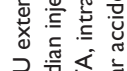

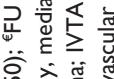

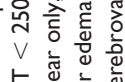

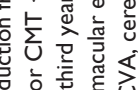

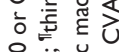

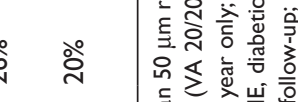

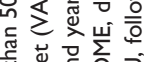

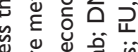

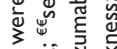

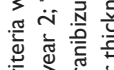

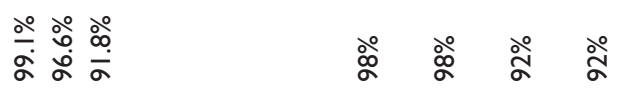

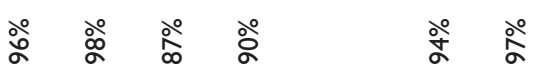

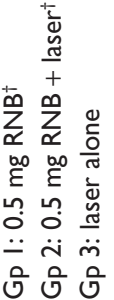
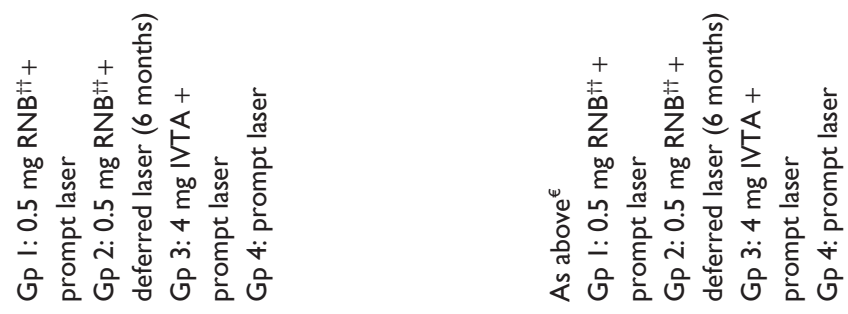

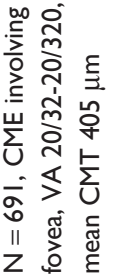

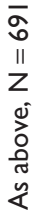

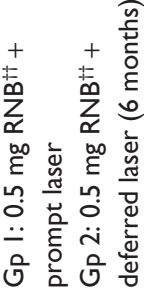

至

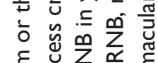

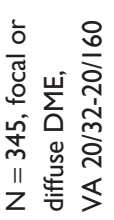
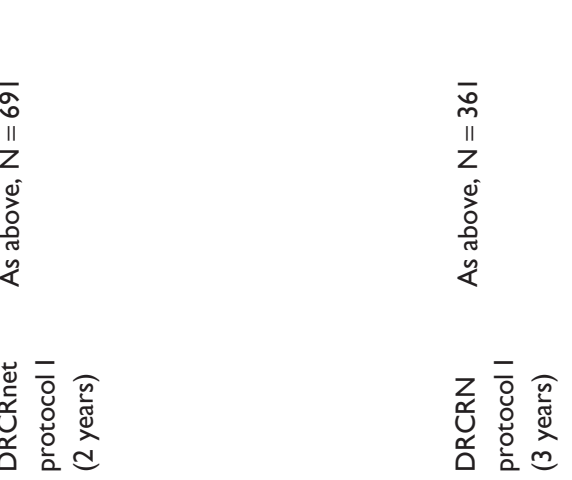

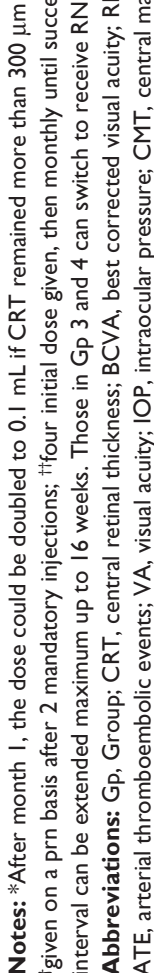

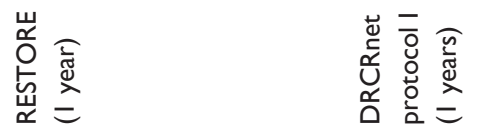


the placebo group. Ranibizumab-treated patients underwent significantly fewer macular laser procedures, with a mean of $0.3-0.8$ in the ranibizumab groups compared with $1.6-1.8$ for the placebo groups. In addition, ranibizumab-treated groups also had significantly greater reductions in macular edema on OCT. The treatment was found to be safe with low incidence of postinjection endophthalmitis. There was no significant increase in the incidence of deaths, nonfatal myocardial infarction, or cerebrovascular accidents, which were known possible systemic side effects of anti-VEGF therapy. Based on these results, the US Food and Drug Administration approved $0.3 \mathrm{mg}$ ranibizumab for the treatment of DME in August 2012.

\section{RESTORE}

The RESTORE study is a 12-month, double-masked, multicentered, laser-controlled Phase III study which evaluated the efficacy and safety of ranibizumab versus laser therapy for DME. ${ }^{28}$ A total of 345 patients with DME were randomized to either ranibizumab $0.5 \mathrm{mg}$, ranibizumab $0.5 \mathrm{mg}$ plus laser, or laser alone. For patients receiving ranibizumab, after two mandatory injections, patients were reinjected on a prn basis according to vision stability and OCT findings. No further injections were given if vision was stable for two consecutive visits or at 20/20. For the laser group, laser therapy was given every 3 months on a prn basis. Results showed that treatment with ranibizumab both as monotherapy or combined treatment were significantly better than laser monotherapy in terms of VA functionally and OCT findings anatomically. At 1 year, the mean average change in VA from baseline was $+6.1,+5.9$, and +0.8 for the ranibizumab monotherapy, ranibizumab plus laser, and laser groups, respectively. Anatomically, the mean CRT decreased by $118.7 \mu \mathrm{m}, 128.3 \mu \mathrm{m}$, and $61.3 \mu \mathrm{m}$ for the ranibizumab, combined, and laser groups, respectively. Patients received a mean of seven injections throughout the 12 months. No significant difference was observed in terms of efficacy between the ranibizumab monotherapy group and the combined ranibizumab and laser groups. Repeated intravitreal injection of ranibizumab was found to be safe with no cases of endophthalmitis. No ocular severe adverse event was observed in the ranibizumab arm, with only one case of increased intraocular pressure, which resolved spontaneously. The pooled incidence of endophthalmitis in the RESOLVE and RESTORE trials was $1.4 \%$, which was similar to the AMD trials. Ranibizumab was not found to be associated with increased risk of cerebrovascular or cardiovascular events in DME patients over 12 months in the study.
For the 303 patients who have completed the RESTORE core study, 240 entered an open-label extension study in which patients received 24-month of monthly $0.5 \mathrm{mg}$ ranibizumab on a prn basis. ${ }^{46}$ Results showed that a mean of 3.7 ranibizumab injections in the second year and 2.7 injections in the third year is sufficient to maintain the mean VA gained in the core study. The safety profile was also satisfactory in the long-term with no new safety concern. The results provided good evidence that long-term treatment with ranibizumab is effective and safe for the treatment of DME.

\section{REVEAL}

The REVEAL study is a multicentered Phase III study similar to RESTORE which compared the efficacy and safety of $0.5 \mathrm{mg}$ ranibizumab as monotherapy or combined with laser versus laser monotherapy in Asian patients with DME. ${ }^{47}$ Over 390 patients were randomized to the three groups and followed for 1 year. At 1 year, ranibizumab alone or combined with laser led to rapid and significant improvement in mean bestcorrected VA compared with laser monotherapy $(P<0.0001)$. The mean visual gain for the ranibizumab and combined groups were 6.6 and 6.4 letters, respectively, while the laser monotherapy group gained 1.8 letters. The mean OCT CRT at 12 months for ranibizumab monotherapy or combined groups were also significantly lower compared with the laser-alone group $(P<0.001)$. In terms of safety, the incidences of ocular and nonocular serious adverse events were similar across all three treatment arms. The findings of the REVEAL are consistent with the RESTORE trial; that ranibizumab monotherapy can result in rapid and significant improvement in vision and reduction in CRT compared with laser alone.

\section{DRCRnet protocol I}

The Diabetic Research Clinical Research Network (DRCRnet) protocol I is a multicentered randomized, controlled trial which assessed the efficacy of intravitreal $0.5 \mathrm{mg}$ ranibizumab combined with prompt or deferred (6 months later) focal/grid laser treatment, $4 \mathrm{mg}$ triamcinolone combined with prompt laser treatment, or prompt focal/grid laser treatment alone for the treatment of central involving DME. ${ }^{48}$ A total of 691 patients (854 eyes) with central involvement DME were recruited. In the ranibizumab arm, four initial doses were given, followed by additional monthly injection if the eye improved (CMT decreased by $\geq 10 \%$ or VA improved by 5 letters compared with the last visit), until success criteria were met (VA of 20/20 or CMT $<250 \mu \mathrm{m}$ ). At the end of 1 year, eyes which had intravitreal ranibizumab with prompt 
or deferred laser had significantly better VA compared with prompt laser alone.

The study was subsequently extended from the original 3 years to 5 years, with eyes in the ranibizumab with prompt or deferred laser continued on their original randomization, while the triamcinolone or laser-alone groups can choose to receive ranibizumab with prompt laser treatment. In the second year, visit intervals could be extended to 8 weeks if injections could be deferred at three consecutive visits, and if ranibizumab was not resumed, the follow-up interval could be extended to every 16 weeks until ranibizumab was resumed. The 2-year visual outcomes were similar to that of the first year. ${ }^{49}$ Compared with prompt laser alone, the mean VA was 3.7 and 5.8 letters better in the ranibizumab with prompt laser and deferred laser groups, respectively, compared with laser alone, while the triamcinolone plus prompt laser group had a mean of 1.5 letters less than the laser control group. In this trial, the median number of injections in the second year was two and three for the ranibizumab with prompt and deferred arms, respectively. This shows that patients in the second year needed substantially fewer injections to maintain the vision gain following the DRCRnet treatment algorithm.

At 3 years, the study compared the VA and OCT outcomes of eyes originally assigned to the ranibizumab prompt laser group (144 patients) versus deferred laser group (147 patients). ${ }^{29}$ Results showed a median of one and two ranibizumab injections for the prompt and deferred laser groups, respectively. The mean VA gain from baseline was 6.8 and 9.7 letters for prompt and deferred laser groups and the difference was statistically significant $(P=0.02)$. Regarding safety, no significant difference was found between the treatment groups. The rate of injection-related endophthalmitis remained low at $0.5 \%$ and $1 \%$ in the prompt and deferred laser groups, respectively.

Using the DRCRnet protocol I retreatment algorithm, the frequency of intravitreal injections could be reduced while maintaining the VA. There was a median of six injections for first 6 months, three in the second 6 months, two or three injections in the second year, and one or two injections in the third year. Despite the decreasing frequency of injections, the VA gained in the first 6 months persisted through the 3 -year study period, suggesting a long-lasting treatment effect of ranibizumab in DME by using this treatment algorithm. This contrasts with neovascular AMD where the visual benefits could not be maintained if the frequency of ranibizumab injection was decreased and illustrates the differences in the strategy in using anti-VEGF therapy for DME and neovascular AMD.

\section{Cost-effectiveness of ranibizumab treatment \\ Age-related macular degeneration}

As AMD is one of the leading causes of blindness worldwide, the burden of disease associated with visual impairment is enormous. Multiple studies have been conducted to estimate the cost-effectiveness of ranibizumab for AMD, and was found to be cost-effective compared with usual care, no treatment, or placebo in Canada, Germany, UK and US when outcomes were calculated on a long-term ( $>10$ year) basis..$^{50}$ Most cost-effectiveness studies used data from the MARINA and ANCHOR trials with monthly ranibizumab injections. In the UK, the incremental cost-effectiveness ratio (ICER), or cost per quality-adjusted life year (QALY) gained for ranibizumab for the treatment of classic CNV, ranged from approximately US\$266,035 for the 2-year model to approximately US\$50,386 for the 10-year model. ${ }^{51}$ Similarly, the ICERs for ranibizumab for patients with minimally classic and occult $\mathrm{CNV}$, compared with usual care, ranged from approximately US\$152,464 for the 2-year model to US\$25,098 for the 10 -year model. ${ }^{51}$ In Canada, the Canadian Agency for Drugs and Technologies in Health evaluated the manufacturer's cost-effectiveness data and found that ranibizumab was cost-effective if the Product Listing Agreement was implemented, ie, the manufacturer pays for additional treatments if the number of injections exceeds nine in the first year and six in the second and third years. ${ }^{50}$

Markov modeling has been used to simulate real-life treatment patterns and effectiveness of ranibizumab treatment for neovascular AMD in Germany. ${ }^{52}$ It predicted VA and costs of patients treated with ranibizumab over 10 years, assuming five injections per year over 2 years versus costs per year of legal blindness avoided (vision year gained) and per QALY. The calculated ICER from the study was approximately US\$17,798-67,562 for all subtypes of CNV.

\section{Diabetic macula edema}

The cost effectiveness of ranibizumab in DME was evaluated from evidence gathered in the RESTORE trial. ${ }^{53}$ Using a Markov model simulating a 15-year time frame for treating DME in one eye using 2010 price levels, it was found that the ICER of ranibizumab monotherapy was approximately US $\$ 39,072$ compared to laser monotherapy. This is equivalent to a $64 \%$ probability of being cost-effective. For the combined laser ranibizumab and laser therapy, it resulted in an ICER of approximately US\$7,635 with a 42\% probability of being cost effective. Therefore, it was concluded that ranibizumab monotherapy appears to be cost effective in 
relation to laser monotherapy, while the cost-effectiveness of combined ranibizumab plus laser therapy was less certain.

\section{Comparative vision gains and impact on quality of life after ranibizumab treatment} Age-related macular degeneration

Patients reported vision-related function and quality of life in the ANCHOR and MARINA trials were assessed using the National Eye Institute 25-item Visual Function Questionnaire (NEI VFQ-25). ${ }^{54}$ It was found that at 12 months, patients treated with $0.3 \mathrm{mg}$ and $0.5 \mathrm{mg}$ ranibizumab had mean improvements in NEI VFQ-25 composite scores of 5.9 and 8.1 points, respectively, compared with 2.2 points improvement in the PDT group. This improvement was seen up to 24 months as ranibizumab-treated patients were more likely to report improved visual function in near and distant related activities and reduced vision-related dependency. ${ }^{54}$ This finding appeared to be valid regardless of whether the treated eye was the better or worse seeing eye at the onset of treatment. ${ }^{55}$ In addition, treatment of neovascular AMD with ranibizumab increased the proportion of patients who have at least 20/40 vision and they were more likely to be driving $(78.4 \%$ in ranibizumab-treated versus $67.2 \%$ in placebo control groups in MARINA; $91.4 \%$ in ranibizumabtreated versus $71.6 \%$ in PDT groups in ANCHOR), as well as reported to have better driving perception. ${ }^{56}$

In a prospective noncomparative consecutive case series, ranibizumab treatment for 3 months was found to improve the near vision of neovascular AMD patients by 33\% compared with baseline, with $44 \%$ increase in reading speed and $33 \%$ improvement in their central visual field. ${ }^{57}$ The quality of life assessed by the NEI VFQ-25 also showed improvement for both distance and near activities. The improvement however was more marked for near activities compared with distance activities.

Quality of life measures following ranibizumab therapy has also been compared with bevacizumab in the IVAN study. ${ }^{15}$ It found that the ranibizumab- and bevacizumabtreated groups did not differ in terms of quality of life scores, contrast sensitivity, and reading index. However, bevacizumab seemed to fare slightly worse in terms of near VA, but the difference failed to reach statistical significance $(P=0.058) .^{18}$

\section{Diabetic macular edema}

The use of ranibizumab has been found to provide healthrelated quality of life gains in patients with DME. In the
RESTORE study, vision-related quality of life gains assessed using the NEI VFQ-25 questionnaire showed significant improvement in patients treated with ranibizumab (monotherapy or combined with laser).$^{53}$ At 1 year, the composite scores increased by 5.0 and 5.4 points in the ranibizumab monotherapy and ranibizumab plus laser groups, respectively, compared with a small gain of 0.6 point in the laser monotherapy group. Vision improved in the ranibizumab group for both distant and near activities. At 12 months, 46\% and $50 \%$ of patients in the ranibizumab monotherapy and combined ranibizumab plus laser groups reported excellentto-good eyesight ( $21 \%$ and $23 \%$ at baseline), compared with $24 \%$ in the laser-only group with a baseline of $22 \%$.

\section{Conclusions and future directions}

The long-term safety and efficacy in the use of ranibizumab for the treatment of neovascular AMD and DME is now being evaluated through the LUMINOUS program. ${ }^{58}$ The study will be a 5-year prospective multicentered noninterventional study to assess the long-term safety, efficacy, treatment patterns, and health-related quality of life outcomes in patients being treated with ranibizumab. With a planned sample size of 30,000 subjects worldwide, the study will help to evaluate the long-term safety and efficacy in addition to understanding the treatment patterns and outcomes of ranibizumab for neovascular AMD and DME in the real-world clinical setting.

More recently, VEGF-trap aflibercept (Eylea, Regeneron, Tarrytown, NY, USA; Bayer Pharma AG, Berlin, Germany), a fusion protein which inhibits both VEGF-A, VEGF-B and $\mathrm{PlGF}$ has been approved by various regulatory authorities for the treatment of neovascular AMD. The approval was based on two Phase III randomized controlled trials, VIEW-1 and VIEW-2, ${ }^{59}$ which evaluated the efficacy and safety of aflibercept in the treatment of neovascular AMD. It compared the use of $0.5 \mathrm{mg}$ aflibercept monthly, $2 \mathrm{mg}$ aflibercept monthly, $2 \mathrm{mg}$ aflibercept bimonthly doses after three initial doses, and $0.5 \mathrm{mg}$ ranibizumab monthly for 2 years. The results showed that all aflibercept treatment groups were noninferior compared with ranibizumab monthly treatment, offering the potential for decreasing the frequency of injection and follow-up visits while maintaining vision gain with the use of aflibercept. Aflibercept has also been reported to result in rapid resolution of persistent macular thickening due to $\mathrm{CNV}$ despite multiple prior ranibizumab injections. ${ }^{60}$ Therefore, aflibercept might provide an alternative treatment option for treatment failures following ranibizumab therapy. The longterm safety of aflibercept however remains to be evaluated. An European public assessment report on aflibercept recently 
published by the European Medicines Agency has reported a higher number of cerebrovascular events in the aflibercept group compared with ranibizumab group, especially in the subgroup of patients $\geq 85$ years $(9.5 \%$ for aflibercept versus $3.4 \%$ for ranibizumab at 2 years). ${ }^{61} \mathrm{~A}$ noninterventional postmarketing study on the use of aflibercept will be conducted to address the risk of arterial thromboembolic events, cerebral vascular accidents, and transient ischemic attacks in the near future.

Based on the various studies with long-term follow-up, there is good evidence that ranibizumab is an effective, safe, and well-tolerated treatment option for both neovascular AMD and DME. Ranibizumab provides not only visual stabilization but also vision gain in neovascular AMD, which has never been achieved with previous treatment modalities. In the long-term, ranibizumab also improves patients' quality of life in various activities and has been shown to be costeffective in both neovascular AMD and DME compared with usual care. Its main drawback is the monthly dosing regimen, which escalates the medical burden of treatment. This is particularly troublesome for neovascular AMD patients as visual deterioration is observed with less frequent dosing of ranibizumab. For DME, the initial gain in VA could be maintained in the long-term with patients requiring much fewer injections after the first year. With numerous new drugs being developed in the research pipeline, treatment options which require less frequent dosing while offering long-term control of disease activities will be more promising therapeutic options for neovascular AMD and DME. However, for the time being, ranibizumab will remain the gold-standard treatment for neovascular AMD and DME due to its good long-term efficacy and safety profiles and will be the yardstick for new treatments to compare with.

\section{Disclosure}

Dr Lai has received honorarium for consultancy and lecture fees from Allergan Inc, Bayer Healthcare, Heidelberg Engineering, and Novartis Pharmaceutical Inc. Dr Fong has no conflicts of interest in this work.

\section{References}

1. Smith W, Assink J, Klein R, et al. Risk factors for age-related macular degeneration: pooled findings from three continents. Ophthalmology. 2001;108(4):697-704.

2. Cheung CM, Tai ES, Kawasaki R, et al. Prevalenec of and risk factors for age-related macular degeneration in a multiethnic Asian cohort. Arch Ophthalmol. 2012;130(4):480-486.

3. Klein R, Klein BE, Knudtson MD, Meuer SM, Swift M, Gangnon RE. Fifteen-year cumulative incidence of age-related macular degeneration: the Beaver Dam Eye Study. Ophthalmology. 2007; 114(2):253-262.
4. Wong TY, Chakravarthy U, Klein R, et al. The natural history and prognosis of neovascular age-related macular degeneration: a systematic review of the literature and meta-analysis. Ophthalmology. 2008;115(1): 116-126.

5. Ferrara N, Damico L, Shams N, Lowman H, Kim R. Development of ranibizumab, an anti-vascular endothelial growth factor antigen binding fragment, as therapy for neovascular age-related macular degeneration. Retina. 2006;26(8):859-870.

6. Lopez PF, Sippy BD, Lambert HM, et al. Transdifferentiated retinal pigment epithelial cells are immunoreactive for vascular endothelial growth factor in surgically excised age-related macular degenerationrelated choroidal neovascular membranes. Invest Ophthalmol Vis Sci. 1996;37(5):855-868.

7. Donoso LA, Kim D, Frost A, et al. The role of inflammation in the pathogenesis of age-related macular degeneration. Surv Ophthalmol. 2006;51(2):137-152.

8. Chan WM, Lai TY, Tano Y, Liu DT, Li KK, Lam DS. Photodynamic therapy in macular diseases of asian populations: when East meets West. Jpn J Ophthalmol. 2006;50(2):161-169.

9. Bressler NM. Photodynamic therapy of subfoveal choroidal neovascularization in age-related macular degeneration with verteporfin: two-year results of 2 randomized clinical trials-tap report 2. Arch Ophthalmol. 2001;119(2):198-207.

10. Bressler NM. Verteporfin therapy of subfoveal choroidal neovascularization in age-related macular degeneration: two-year results of a randomized clinical trial including lesions with occult with no classic choroidal neovascularization-verteporfin in photodynamic therapy report 2. Am J Ophthalmol. 2002;133(1):168-169.

11. Brown DM, Michels M, Kaiser PK, Heier JS, Sy JP, Ianchulev T. Ranibizumab versus verteporfin photodynamic therapy for neovascular age-related macular degeneration: two-year results of the ANCHOR study. Ophthalmology. 2009;116(1):57-65. e55.

12. Rosenfeld PJ, Brown DM, Heier JS, et al. Ranibizumab for neovascular age-related macular degeneration. N Engl J Med. 2006;355(14): 1419-1431.

13. Regillo CD, Brown DM, Abraham P, et al. Randomized, doublemasked, sham-controlled trial of ranibizumab for neovascular agerelated macular degeneration: PIER Study year 1. Am J Ophthalmol. 2008;145(2):239-248.

14. Lalwani GA, Rosenfeld PJ, Fung AE, et al. A variable-dosing regimen with intravitreal ranibizumab for neovascular age-related macular degeneration: year 2 of the PrONTO Study. Am J Ophthalmol. 2009;148(1):43-58.

15. Holz FG, Amoaku W, Donate J, et al. Safety and efficacy of a flexible dosing regimen of ranibizumab in neovascular age-related macular degeneration: the SUSTAIN study. Ophthalmology. 2011;118(4):663-671.

16. Singer MA, Awh CC, Sadda S, et al. HORIZON: an open-label extension trial of ranibizumab for choroidal neovascularization secondary to age-related macular degeneration. Ophthalmology. 2012;119(6): 1175-1183.

17. CATT Research Group, Martin DF, Maguire MG, et al. Ranibizumab and bevacizumab for neovascular age-related macular degeneration. N Engl J Med. 2011;364(20):1897-1908.

18. Chakravarthy U, Harding SP, Rogers CA, et al. Ranibizumab versus bevacizumab to treat neovascular age-related macular degeneration: one-year findings from the IVAN randomized trial. Ophthalmology. 2012;119(7):1399-1411.

19. Yau JW, Rogers SL, Kawasaki R, et al. Global prevalence and major risk factors of diabetic retinopathy. Diabetes Care. 2012;35(3):556-564.

20. Cheung N, Mitchell P, Wong TY. Diabetic retinopathy. Lancet. 2010;376(9735):124-136.

21. Photocoagulation for diabetic macular edema. Early Treatment Diabetic Retinopathy Study report number 1. Early Treatment Diabetic Retinopathy Study research group. Arch Ophthalmol. 1985;103(12): 1796-1806.

22. Grover D, Li TJ, Chong CC. Intravitreal steroids for macular edema in diabetes. Cochrane Database Syst Rev. 2008;1:CD005656. 
23. Do DV, Nguyen QD, Khwaja AA, et al. Ranibizumab for edema of the macula in diabetes study: 3-year outcomes and the need for prolonged frequent treatment. Arch Ophthalmol. 2013;131(2):139-145.

24. Nguyen QD, Brown DM, Marcus DM, et al. Ranibizumab for diabetic macular edema: results from 2 phase III randomized trials: RISE and RIDE. Ophthalmology. 2012;119(4):789-801.

25. Nguyen QD, Shah SM, Heier JS, et al. Primary end point (six months) results of the ranibizumab for edema of the macula in diabetes (READ-2) study. Ophthalmology. 2009;116(11):2175-2181.

26. Nguyen QD, Shah SM, Khwaja AA, et al. Two-year outcomes of the ranibizumab for edema of the mAcula in diabetes (READ-2) study. Ophthalmology. 2010;117(11):2146-2151.

27. Massin P, Bandello F, Garweg JG, et al. Safety and efficacy of ranibizumab in diabetic macular edema (RESOLVE Study): a 12-month, randomized, controlled, double-masked, multicenter phase II study. Diabetes Care. 2010;33(11):2399-2405.

28. Mitchell P, Bandello F, Schmidt-Erfurth U, et al. The RESTORE study: ranibizumab monotherapy or combined with laser versus laser monotherapy for diabetic macular edema. Ophthalmology. 2011;118(4):615-625.

29. Elman MJ, Qin H, Aiello LP, et al. Intravitreal ranibizumab for diabetic Macular edema with prompt versus deferred laser treatment: three-year randomized trial results. Ophthalmology. 2012;119(11):2312-2318.

30. Ferrara N. Vascular endothelial growth factor: basic science and clinical progress. Endocr Rev. 2004;25(4):581-611.

31. Stewart MW. The expanding role of vascular endothelial growth factor inhibitors in ophthalmology. Mayo Clin Proc. 2012;87(1):77-88.

32. Gragoudas ES, Adamis AP, Cunningham ET Jr, Feinsod M, Guyer DR; VEGF Inhibition Study in Ocular Neovascularization Clinical Trial Group. Pegaptanib for neovascular age-related macular degeneration. N Engl J Med. 2004;351(27):2805-2816.

33. Blick SK, Keating GM, Wagstaff AJ. Ranibizumab. Drugs. 2007; 67(8):1199-1206.

34. Kim KJ, Li B, Winer J, et al. Inhibition of vascular endothlial growth factor-induced angiogenesis suppresses tumor growth in vivo. Nature. 1993;362(6423):841-844.

35. Presta LG, Chen H, O'Connor SJ, et al. Humanization of an antiVEGF monoclonal antibody for the therapy of solid tumours and other disorders. Cancer Res. 1997;57(20):4593-4599.

36. Ferrara N, Kerbel RS. Angiogenesis as a therapeutic agent. Nature 2005;438(7070):967-974.

37. Frampton JE. Ranibizumab: in diabetic macular oedema. Drugs. 2012;72(4):509-523.

38. Lowe J, Araujo J, Yang J, et al. Ranibizumab inhibits multiple forms of biologically active vascular endothelial growth factor in vitro and in vivo. Exp Eye Res. 2007;85(4):425-430.

39. Gaudreault J, Fei D, Rusit J, Suboc P, Shiu V. Preclinical pharmacokinetics of Ranibizumab (rhuFabV2) after a single intravitreal administration. Invest Ophthalmol Vis Sci. 2005;46(2):726-733.

40. Gaudreault J, Fei D, Beyer JC, et al. Pharmacokinetics and retinal distribution of ranibizumab, a humanized antibody fragment directed against VEGF-A, following intravitreal administration in rabbits. Retina. 2007;27(9):1260-1266.

41. Krohne TU, Liu Z, Holz FG, Meyer CH. Intraocular pharmacokinetics of ranibizumab following a single intravitreal injection in humans. Am J Ophthalmol. 2012;154(4):682-686

42. Xu L, Lu T, Tuomi L, et al. Pharmacokinetics of ranibizumab in patients with neovascular age-related macular degeneration - a population approach. Invest Ophthalmol Vis Sci. 2013;54(3):1616-1624.

43. Boyer DS, Heier JS, Brown DM, Francom SF, Ianchulev T, Rubio RG. A Phase IIIb study to evaluate the safety of ranibizumab in subjects with neovacsular age-related macular degeneration. Ophthalmology. 2009;116(9):1731-1739.

44. Martin DF, Maguire MG, Fine SL, et al. Ranibizumab and bevacizumab for treatment of neovascular age-related macular degeneration: two-year results. Ophthalmology. 2012;119(7):1388-1398.
45. Schmucker C, Ehlken C, Agostini HT, et al. A safety review and meta-analyses of bevaizumab and ranibizumab: off-label versus gold standard. PLoS ONE. 2012;7(8):e42701.

46. Mitchell P; RESTORE extension study group. 2-year safety and efficacy outcome of ranibizumab $0.5 \mathrm{mg}$ in patients with visual impairment due to diabetic macular edema (DME): an interim analysis of the RESTORE extension study. Invest Ophthalmol Vis Sci. 2012;53:ARVO E-abstract 4667.

47. Ohji M, Ishibashi T; REVEAL study group. Efficacy and safety of ranibizumab $0.5 \mathrm{mg}$ as monotherapy or adjunctive to laser versus laser monotherapy in Asian patients with visual impairment due to diabetic macular edema: 12-month results of the REVEAL study. Invest Ophthalmol Vis Sci. 2012;53:ARVO E-abstract 4664.

48. Elman MJ, Aiello LP, Beck RW, et al. Randomized trial evaluating ranibizumab plus prompt or deferred laser or triamcinolone plus prompt laser for diabetic macular edema. Ophthalmology. 2010;117(6): 1064-1077. e1035.

49. Elman MJ, Bressler NM, Qin H, et al. Expanded 2-year follow-up of ranibizumab plus prompt or deferred laser or triamcinolone plus prompt laser for diabetic macular edema. Ophthalmology. 2011; 118(4):609-614.

50. Mitchell P, Annemans L, White R, Gallagher M, Thomas S. Cost effectiveness of treatments for wet age-related macular degeneration. Pharmacoeconomics. 2011;29(2):107-131.

51. Colquitt JL, Jones J, Tan SC, Takeda A, Clegg AJ, Price A. Ranibizumab and pegaptanib for the treatment of age-related macular degeneration: a systematic review and economic evaluation. Health Technol Assess. 2008;12(16):iii-iv,ix-201.

52. Neubauer AS, Holz FG, Sauer S, et al. Cost-effectiveness of ranibizumab for the treatment of neovascular age-related macular degeneration in Germany: model analysis from the perspective of Germany's statutory health insurance system. Clin Ther. 2010;32(7): 1343-1356.

53. Mitchell P, Annemans L, Gallagher M, et al. Cost-effectiveness of ranibizumab in treatment of diabetic macular oedema (DME) causing visual impairment: evidence from the RESTORE trial. Br JOphthalmol. 2012;96(5):688-693.

54. Bressler NM, Chang TS, Fine JT, Dolan CM, Ward J. Improved visionrelated function after ranibizumab vs photodynamic therapy: a randomized clinical trial. Arch Ophthalmol. 2009;127(1):13-21.

55. Bressler NM, Chang TS, Suner IJ, et al. Vision-related function after ranibizumab treatment by better- or worse-seeing eye: clinical trial results from MARINA and ANCHOR. Ophthalmology. 2010;117(4): 747-756.

56. Bressler NM, Chang TS, Varma R, et al. Driving ability reported by beovascular age-related macular degeneration patients after treatment with ranibizumab. Ophthalmology. 2013;120(1):160-168.

57. Frennesson C, Nilsson UL, Peebo BB, Nilsson SE. Significant improvements in near vision, reading speed, central visual field and related quality of life after ranibizumab treatment of wet age-related macular degeneration. Acta Ophthalmol. 2010;88(4):420-425.

58. Bandello F, Holz FG, Gillies MC, Koh A, Mitchell P; LUMINOUS group, Safety, efficacy, treatment patterns of ranibizumab therapy for neovascular age-related macular degneration: the LUMINOUS studies. Invest Ophthalmol Vis Sci. 2012;53:ARVO E-abstract 2031.

59. Heier JS, Brown DM, Chong V, et al. Intravitreal aflibercept (VEGF Trap-Eye) in wet age-related macular degeneration. Ophthalmology. 2012;119(12):2537-2548.

60. Chaikitmongkol V, Bressler NM. Dramatic resolution of choroidal neovascular abnormalities after single aflibercept injection following years of ranibizumab use. JAMA Ophthalmol. 2013;131(2):260-262.

61. European Medicines Agency. Eylea: EPAR - public assessment report. EMA/646256/2012 corr. September 20, 2012. Available from: http:// www.ema.europa.eu/docs/en_GB/document_library/EPAR_-_Public_assessment_report/human/002392/WC500135744.pdf. Accessed April 17, 2013. 
Clinical Interventions in Aging

\section{Publish your work in this journal}

Clinical Interventions in Aging is an international, peer-reviewed journal focusing on evidence-based reports on the value or lack thereof of treatments intended to prevent or delay the onset of maladaptive correlates of aging in human beings. This journal is indexed on PubMed Central, MedLine, the American Chemical Society's 'Chemical Abstracts

Service' (CAS), Scopus and the Elsevier Bibliographic databases. The manuscript management system is completely online and includes a very quick and fair peer-review system, which is all easy to use. Visit $\mathrm{http}: / /$ www.dovepress.com/testimonials.php to read real quotes from published authors.

Submit your manuscript here: http://www.dovepress.com/clinical-interventions-in-aging-journal 